\title{
Linfoma De Colo Uterino: Relato De Caso.
}

\author{
Antunes, P.N.; Dornelles, M.A.; Fernandes, L.P.; Dutra, P.L.; Kretzer, S.S.; Dal \\ Molin, R.K.; Victorino, J.A.; \\ Apresentador: Priscila Nunes Antunes
}

\section{Resumo}

Introdução: Linfoma do trato genital feminino é doença rara, perfazendo menos de $0,5 \%$ das neoplasias ginecológicas. Sítios mais comumente acometidos são ovários e útero. Método: Relato de caso. Resultados: Mulher de 50 anos com dor abdominal difusa e constante há 1 mês, mais intensa em hipogastro com irradiação para dorso associada à náuseas, além de menorragia recente, leucorreia e tenesmo vesical sem febre, perda ponderal, anorexia ou alteração do hábito intestinal. Eutrófica, abdome com massa palpável pouco dolorosa em hipogastro com extensão até a cicatriz umbilical, mais proeminente em flanco e região inguinal direita, linfonodos inguinais palpáveis bilateralmente. Tomografia computadorizada (TC) abdominal: lesão expansiva em topografia de colo uterino com realce heterogêneo pelo contraste de 7,8 x 9,0cm diâmetro de provável natureza neoplásica, infiltrativa na parede posterior da bexiga determinando hidronefrose à direita. Exame especular: massa volumosa com importante área de necrose ocupando colo uterino em toda sua extensão. Ecografia transvaginal não realizada devido à impossibilidade de progressão do transdutor. Citopatológico de colo uterino de 1 ano antes negativo para malignidade. Função renal normal, sem anemia ou leucocitose/leucopenia.
Realizada nefrostomia percutânea e biópsia de colo uterino (anatomopatológico: neoplasia maligna de células pequenas, considerar linfoma não- Hodgkin de alto grau e carcinoma neuroendócrino de pequenas células). Imunohistoquímica compatível com linfoma B difuso de grandes células. Líquor com blastos, biópsia de medula óssea com infiltração pela mesma neoplasia, tomografia por emissão de pósitrons compatível com doença avançada. Iniciada quimioterapia (QT) com pequena redução tumoral, sem melhora na qualidade de vida. Em uso de QT intratecal, evoluiu com cefaleia, plegia de membro superior esquerdo e trismo. TC crânio sem hemorragia, líquor sem alterações. Ressonância magnética crânio: áreas extensas de restrição à difusão da água comprometendo substância branca no centro bilateralmente de modo mais extenso à direita. Paciente apresentou piora neurológica progressiva, rigidez de nuca e arreflexia, sendo necessária intubação nasotraqueal. Estabelecida neurotoxicidade devastadora secundária à QT, prognóstico tornou-se reservado. Conclusão: Linfoma primário do colo uterino é muito raro, sendo o linfoma de grandes células B o mais frequente. Pela raridade do diagnóstico, o tratamento não está bem definido.

\section{Referência:}

Antunes, P.N.; Dornelles, M.A.; Fernandes, L.P.; Dutra, P.L.; Kretzer, S.S.; Dal Molin, R.K.; Victorino, J.A.; Linfoma De Colo Uterino: Relato De Caso.. In: II Congresso Brasileiro de Medicina Hospitalar - II CBMH [= Blucher Medical Proceedings, vol.1, num.5] São Paulo: Editora Blucher, 2014. p.18

DOI 10.5151/medpro-II-cbmh-009 